\title{
Developments of Gussasphalt System on Steel Deck Pavement
}

\author{
Min Wang1, Deyong Hu², Li Xiao², Fei Shang² \\ ${ }^{1}$ China Merchants Chongqing Communications Research \& Design Institute Co., Ltd., Chongqing, China \\ ${ }^{2}$ Chongqing Zhixiang Paving Technology Engineering Co., Ltd., Chongqing, China \\ Email: panda9496@163.com, hudeyong@cmhk.com,xiaoli1@cmhk.com, zxshangfei@cmhk.com
}

How to cite this paper: Wang, M., Hu, D.Y., Xiao, L. and Shang, F. (2017) Developments of Gussasphalt System on Steel Deck Pavement. World Journal of Engineering and Technology, 5, 141-147. https://doi.org/10.4236/wjet.2017.53B016

Received: July 14, 2017

Accepted: August 28, 2017

Published: August 31, 2017

\begin{abstract}
With the development of steel deck paving technology, the associated gussasphalt pavement system also develops maturely. In this paper, the structure characteristics and performance advantages are thoroughly explained by introducing the development course of gussasphalt. The material composition, properties and application effect of three typical pavement methods are analyzed. This paper is intended to give a relatively clear understanding regarding the specific features of gussasphalt, and provide some guidance to further expansion concerning gussasphalt pavement.
\end{abstract}

\section{Keywords}

Steel Deck, Gussasphalt, Pavement System, Property, Advantage

\section{Introduction}

Gussasphalt (GA) is derived from the Latin word " $\mathrm{Gu} \beta$ ', which originally means "river", and expands to meaning "pouring and flowing" afterwards. It indicates that gussasphalt has good fluidity, and the installation can be accomplished by simply laying and leveling, without any roller compaction [1] [2].

Gussasphalt pavement is originated in Germany and has been in use for a long period of time. Most projects adopts the gussasphalt pavement method, which is proven to be the most excellent decisions at that time, such as the Colognemulheim Rhine Bridge, the Oberkasseler Briage, the Mulheim Bridge, the Zoo Bridge et al. Subsequently it is widely used in the United Kingdom, Poland, Denmark, Japan, the United States and other developed countries [3].

A Chinese corporation named "China Merchants Chongqing Communications Technology Research \& Design Institute" has introduced the gussasphalt 
pavement technologies from Germany since 2000, and successfully applied in the Shengli Yellow River Highway Bridge Project for the first time in 2003 [4]. After that, gussasphalt pavement system has been used in quite a lot of projects and is continuing to popularize [5] [6].

\section{Composition Characteristics and Performance Advantages of Gussasphalt}

Due to the so called "three-high" characteristic of gussasphalt, high filler content (7\% - 10\%), high bitumen content (20\% - 30\%) and high mixing temperature $\left(220^{\circ} \mathrm{C}-240^{\circ} \mathrm{C}\right)$, coarse aggregates in the mixture are in suspending state. The void fraction of gussasphalt is very small and its pores are disconnected, which is different from hot rolled asphalt mixture [7]. The contrast is shown in Table 1.

The structural feature of gussasphalt determines its special properties that conventional rolled asphalt mixture does not have. It is these performance advantages that meet the requirements of special paving projects, especially steel deck pavement. Compared to traditional asphalt mixture, gussasphalt possesses specific features as follows.

\section{1) Low Water Permeance}

The void fraction of gussasphalt is close to zero. Therefore, the gussasphalt pavement is absolutely impermeable, far better than other type of rolled asphalt mixture would be. In most of cases, gussasphalt has been directly applied as the waterproof material, or as part of waterproofing system.

\section{2) Excellent Durability}

Since the void fraction of gussasphalt is very small and interior pores are disconnected, ambient moisture is unable to pass through inside. As a result, the performance deterioration and material damages caused by moisture or air can be avoided, such as aging, embrittlement, etc. For this purpose, gussasphalt is considered durable.

\section{3) Good Flexibility and Resistance to Fatigue Crack}

Although subject to traffic and climate conditions for a long term, gussasphalt pavement can still remain good flexibility due to its high bitumen content. It is able to tolerate repeated bending deformation without any damages like crack and delaminating.

Table 1. Composition and structure differences of various asphalt mixture.

\begin{tabular}{cccc}
\hline Structure Type & GA10 & SMA10 & AC10 \\
\hline Grading Type & Dense-suspended & Dense-skeleton & Dense-suspended \\
Mixing Temp. $\left({ }^{\circ} \mathrm{C}\right)$ & $220-250$ & $170-185$ & $170-185$ \\
Bitumen Content (\%) & $7-8$ & $5-6$ & $4-5$ \\
0.075 mm Passing Rate (\%) & $24-28$ & $10-13$ & $4-7$ \\
Fine Aggregate Content (\%) & $28-32$ & $12-15$ & $26-31$ \\
\hline
\end{tabular}




\section{4) Good Integrity}

Gussasphalt belongs to a kind of self-leveling materials in the process of installation. This performance allows gussasphalt pavement to have a certain resistance to vertical deformation, and have quite strong cohesion in a horizontal plane. Thus, it ensures the pavement with good integrity.

\section{5) No Damage Caused by Rolling Compaction}

The process of molding and strength forming are spontaneous after the temperature of gussasphalt falls. There is no need to carry out rolling compaction. In this way, numerous potential risks concerning quality will dissolve into nothingness, such as temperature segregation and aggregate segregation.

In addition, gussasphalt also has the good applicability that most of traditional rolled asphalt mixture does not have. For example, in some special sections, such as sidewalk, central reservation, cable areas, just gussasphalt or similar materials can be used to ensure good construction quality, because mechanical rolling process cannot be applied in these narrow areas.

\section{Development Course of Gussasphalt}

Europe is the earliest and most mature region with respect to research and application of gussasphalt technologies all over the world [8]. Along with the verification of application results in many projects, gussasphalt is gradually introduced and applied in some parts of the United States and Canada, representative projects are Manhattan Bridge and Moruimakan Bridge. Japanese have largely adjusted the material formulation and technical requirements after the introduction of gussasphalt. Subsequently a suite of technologies are generated, which are suitable to Japanese national conditions. In Japan, gussasphalt pavement system has covered nearly 70 percent of steel deck paving projects so far [9].

Gussasphalt is brought in China in the 1990's, and applied to the Jiangyin Yangtze River Bridge in Chinese mainland, the Tsing Ma Bridge in Hongkong, the Xindong Bridge and the Gaoping Briage in Taiwan, respectively. Taking the early application effects into account, double-layer pavement methods related to gussasphalt are very popular in accordance with tough traffic and climate conditions in China. Namely, Gussasphalt is utilized for protective course, other type of asphalt mixture such as Stone Mastic Asphalt (SMA), Epoxy Asphalt Concrete (EA), Open-graded Friction Course (OGFC) or Asphalt Concrete (AC) are used for wearing course.

The development course of domestic gussasphalt can be broadly divided into three phases. The first phase is the introduction of foreign technology. The second phase is optimizing foreign technology combined with Chinese situation. The third phase is the innovation and improving. Different stages reflect different application effects of domestic gussasphalt pavement.

Phase I-the period of introduction (1997-2002). It is the early application stage of gussasphalt in China. Based on the experience and practices of western countries, the mastic asphalt across the UK is introduced. With respect to such 
kind of asphalt mixture, the binder is made up of 70\% natural trinidad lake asphalt (TLA) and 30\% normal bitumen. During that time, the mastic asphalt pavement has been typically applied to the Tsing Ma Bridge in Hong Kong and the Jiangyin Yangtze River Bridge in Jiangsu province, but the latter failed due to heavy traffic and strict climate conditions.

Phase II-the period of optimizing (2003-2007). Relevant research units have made some adjustments regarding structure and key components of gussasphalt, in accordance with domestic service conditions. For instance, the complex modified bitumen instead of common modified bitumen is utilized as asphalt binder, so that the high-temperature performance of gussaphalt shall be improved. Besides, an upper pavement layer is brought into pavement design scheme to improve the resistance to overload, for example, SMA10 with high viscosity bitumen and OGFC.

Phase III-the period of innovation and improving (2008-present). A complete set of gussasphalt technologies have been developed in accordance with complex traffic and climatic conditions in China. Most of problems regarding key materials, equipments, techniques and specifications have been solved during this period. The polymer modified bitumen is adopted as asphalt binder. Meanwhile, the SMA10 with high-elastic bitumen or EA is used for the wearing course. It is applied with automated machinery and equipments to accomplish chippings distribution and rolling compaction. More importantly, a standard called "Specifications for Design and Construction of Highway Steel Bridge Pavement" has been compiled.

\section{Typical Pavement Structure and Application Situation}

After many years of development, a variety of pavement schemes of gussasphaltoriented are at present, so that it can meet different requirements of highway construction.

\subsection{GA + SMA}

The detailed pavement structure is shown in Figure 1.

\begin{tabular}{c|l}
\hline Wearing Course & SMA10 with high-elastic bitumen, 30mm thick \\
\hline Cohesion Layer & Modified Emulsion Asphalt \\
\hline Protective Course & GA10, 5-10mm pre-coated chippings distributed on the surface \\
\cline { 2 - 2 } Waterproofing Layer & Tack coat \\
\cline { 2 - 2 } & Waterproof membrane, two layers \\
\cline { 2 - 2 } Steel Deck & Pandber \\
\hline
\end{tabular}

Figure 1. Pavement structure diagram of GA + SMA with high-elastic bitumen method. 
The wearing course adopts SMA10 with high-elastic bitumen because of its excellent rutting resistance and skid resistance. In addition, the high-elastic modified bitumen is able to overcome the disadvantages of conventional SMA, like poor resistance to fatigue cracks. In other words, the resistance to fatigue cracks shall be greatly improved and deterioration and damages will be avoided. The protective course adopts GA.

The polymethyl methacrylate (PMMA) resin is used for waterproofing layer. It owns not only better performance of anti-corrosion, water tightness and bonding, but also excellent flexibility. The material can adapt well to structural characteristics of orthotropic steel deck, and the properties won't decay under the effect of repeated load.

This pavement method has successfully underwent extensive applications in China. There are over 60 projects with a total pavement area of 1.5 million $\mathrm{m}^{2}$, and the application effects are good.

\subsection{GA + EA}

The detailed pavement structure is shown in Figure 2.

The wearing course adopts EA because of its high strength. The Marshall stability of EA can be up to 3 to 5 times of normal asphalt concrete. It also has good performance of fatigue resistance and corrosion resistance. The protective course adopts GA.

The waterproofing layer adopts epoxy asphalt binder. Since epoxy resin is a kind of reactive material, the mechanical strength can be tremendously enhanced after curing reaction, and the bonding strength with GA is extremely good as well. Furthermore, the epoxy asphalt binder is ductile and could result in good consistent with deformation of steel deck.

At present, this pavement method has been used in the Taizhou Yangtze River Bridge and some middle-small-scale bridges. Most of the projects have achieved an ideal application effects.

\subsection{GA + OGFC}

The detailed pavement structure is shown in Figure 3.

\begin{tabular}{l|l}
\hline Wearing Course & EA10,30mm thick \\
\hline Cohesion Layer & Epoxy asphalt binder, dosage ca. $0.4 \mathrm{~kg} \pm 0.05 \mathrm{~kg}$ \\
\hline Protective Course & GA10, 5-10mm pre-coated chippings distributed on the surface \\
\hline Waterproofing Layer & Epoxy asphalt binder \\
\hline Anti-corrosion Layer & Epoxy zinc rich primer \\
\hline Steel Deck & Sandblasting and Derusting, Cleanliness Sa 2.5, Roughnes: $50-100 \mathrm{~m}$ \\
\hline &
\end{tabular}

Figure 2. Pavement structure diagram of GA + EA method. 


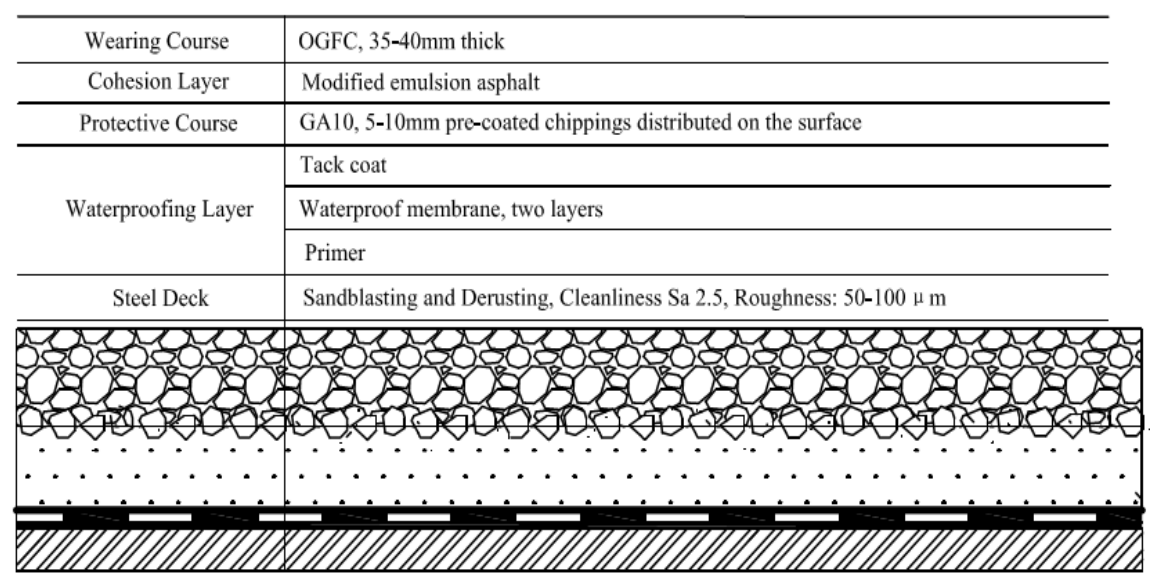

Figure 3. Pavement structure diagram of GA + OGFC method.

The wearing course-OGFC, possesses characteristic of macrovoid and skeleton interlocking. When it rains heavy, the water on the surface of pavement can be quickly drained away, so that the impact of rainfall on traffic safety will be reduced. What's more, it can save asphalt mixture from water damage. Such skeleton interlocking structure of OGFC exhibits good stability at high temperature, which is not easily subject to damages caused by high temperature, for example, rutting.

The protective course GA, together with the waterproofing PMMA material, forms an excellent waterproof system, which can effectively protect elements of the steel bridge.

This pavement method has been used for the Jiahua Bridge in Chongqing, and its application is in good condition up to now.

\section{Prospect and Forecast}

With the continuous improvement of steel deck paving technologies in China, the properties of gussasphalt pavement have been significantly enhanced. The integrated performance even exceeds corresponding foreign products. Gussasphalt has strong suitability for highway and waterproofing projects, especially for steel deck pavement. Currently, the proportion of steel deck pavement related to gussasphalt method has reached a half in Chinese market. There is reason to believe that the gussasphalt pavement method will become the mainstream pavement scheme at home and abroad in future.

However, the actual life span of domestic gussasphalt pavement cannot reach the level of similar pavement at abroad, with the influence of specific traffic and climate conditions, as well as the construction management gap. Besides, the domestic application of gussasphalt is limited to bridge deck pavements, rarely used in other related fields. Therefore, it is imperative to establish the design code and application guide regarding gussasphalt which suits to China's national conditions. And it is very important theoretic value and practicing sense to popularize gussasphalt technology. 


\section{References}

[1] (2005) Research on Deck Pavement Material and Technology. China Merchants Chongqing Communications Research \& Design Institute Co., Ltd.

[2] Wu, W.J., Zhang, H. and Qian, J.S. (2009) A Review of Application Status of Gussasphalt Concrete. Technology of Highway and Transport, No. 3, 59-62.

[3] Fan, Y.H., Huang, W., Wang, J.M., et al. (2007) On Analysis of Road Performance of Steel Deck Gussasphalt Mixture Pavement. Technology of Highway and Transport, No. 4, 24-28.

[4] (2008) A Study on Concrete Deck Pavement Structure and Pavement Technology. China Merchants Chongqing Communications Research \& Design Institute Co., Ltd.

[5] Wang, M., Wu, Z.H. and Li, Y.L. (2008) On Steel Deck Pavement Design and Application of Chongqing Caiyuanba Yangtze Bridge. Technology of Highway and Transport (Technology), No. 9, 127-129.

[6] Zheng, Y. (2013) A Study on High Performance Indicators of Steel Deck Gussasphalt Concrete. Southeast University.

[7] Pi, Y.H. and Chen, S.Z. (2006) On Application of Gussasphalt Concrete to Bridge Deck Pavement. Journal of China and Foreign Highway, No. 1, 155-158.

[8] Puddick, A. (2015) Bridging the Gap: Mastic Asphalt Used in Asphaltic Bridge Joints in the UK. Proceeding of International Mastic Asphalt Association Symposium, 4-5 September 2015, St Petersburg, Russia.

[9] Zhurbin, A. (2015) Use of Mastic Asphalt for Bridge Construction in Russia. Proceeding of International Mastic Asphalt Association Symposium, 4-5 September 2015, St Petersburg, Russia. 